\title{
Pharmacological effects of low doses of some commonly used NSAIDs on ovulation and corpus luteum in mature female mice *Acellular and Hormanal comparative study *
}

\author{
Hebah .M ${ }^{1}$, Al-Falahi . Ahmad .M,Al-Zohyri ${ }^{2}$, And Mohammed \\ Q.Al-Atrakji ${ }^{2}$. \\ Pharmacology, College of Medicine, Baghdada University, Baghdad, Iraq \\ Pharmacology Department, College of Medicine, Baghdada University, Baghdad, Iraq
}

\begin{abstract}
Ovulation constitutes the central event in ovarian physiology, and ovulatory disfunction is a relevant cause of female infertility. Non-steroidal anti-inflammatory drugs (NSAIDs), widely used due to their analgesic and anti-inflammatory properties, consistently inhibit ovulation in all mammalian species investigated so far, likely due to the inhibition of cyclooxygenase that is the rate limiting enzyme in prostaglandin $(P G)$ synthesis.Short-term administration of low-dose (aspirin, mefenamic acid buprofen \& meloxicam) to female mice at proestrous cause a highly significant decrease in the ovulatory rate as compared to controls. Greater effect were produced by meloxicam.
\end{abstract}

\section{Introduction}

The NSAIDs are a group of chemically dissimilar agents that differ in their antipyretic, analgesic, and anti-inflammatory activities (1) the most frequently consumed drugs worldwide. NSAIDs derive much of their anti-inflammatory properties from their capacity to inhibit the synthesis of prostaglandins, have important roles in normal physiology that might best be described as protective in nature, released in response to injury and have the capacity to provoke vasodilatation , erythema, and hyperalgesia(2). Prostaglandin formation is mediated by cyclooxygenase. COX catalyzes the formation of prostaglandins and thromboxane from arachidonic acid ( itself derived from the cellular phospholipid bilayer by phospholipase $A_{2}$ ) (3). There are 2 forms of cyclo-oxygenase (COX), COX-1 (the constitutive form ), and COX-2(the induced form in the presence of inflammation), inhibition of COX-2 is therefore thought to be responsible for at least some of the analgesic, anti-inflammatory, and antipyretic properties of NSAIDs (4). The process of ovulation has all the signs of an acute, self-controlled inflammatory reaction, including hyperaemia, edema, leukocyte extrav -asationand induction of proteolytic and collagenolytic activities $(5,6)$. Prostaglandins, which play a central role in inflammation ,stimulate many periovulatory processes including expansion of the cumulus granulosa cells $(7,8)$, and enhancement of protease activities which degrade extracellular matrix(9). These and other periovulatory processes are essential for successful oocyte release and, therefore, fertility, In periovulatory follicles, the COX2 isoform is responsible for prostaglandin production. COX-2 expression by granulosa cells increases after the ovulatory luteinizing hormone ( $\mathrm{LH})$ surg $(10,11)$. Inhibition of COX-2 activity limits follicular prostaglandin production, prevents follicle rupture and blocks oocyte release supporting a key role for COX-2 in the ovulatory proces $(11,12)$. More recently, genetic studies in mice $(13,14)$ have confirmed the obligatory role of COX-2/ prostaglandins in ovulation. The present study was designed to compare between the effects of some NSAIDs (aspirin ,mefenamic acid ,ibuprofen and meloxicam) on ovulatory process and reproductive tract of female mice.

\section{Material and methods:}

All experiments were started and performed on mature female Swiss white micewith a body weight ranging from 25-30g , provided by Animal breeding at the National Center for control and pharmaceutical resaerch .Drugs used are:Aspirin(Acetyl Salicylic Acid)The preparation used was Aspegic ${ }^{\circledR}$, each vial contains $0.5 \mathrm{~g}$ of A.S.A. for the preparation of the doses used in the study $(2.5 \mathrm{mg} / \mathrm{Kg}$. B.W.), S/C,for oral used the final solution of s.c but double volume. Mefenamic acid the preparation used was fenamic ${ }^{\circledR}$ suspension contain 50 $\mathrm{mg} / 5 \mathrm{ml}$ for the preparation of the doses used in the study $(8.33 \mathrm{mg} / \mathrm{Kg})$. Ibuprofen the preparation used was profinal ${ }^{\circledR}$ suspension contain $100 \mathrm{mg} / 5 \mathrm{ml}$ for the preparation of the doses used in the study $(10 \mathrm{mg} / \mathrm{Kg})$. MeloxicamThe preparation used was mobic ${ }^{\circledR}$ ampoule, each ampoule containing $15 \mathrm{mg} / 1.5 \mathrm{ml}$ for the preparation of the doses used in the study $(0.0033 \mathrm{mg} / \mathrm{kg}$.B.W. $)$ distilled water used for dilution. 


\section{Dose Calculation:}

In orderto determine the dose of (Mefenamic acid \& Ibuprofen) which is comparable to aspirin 2.5 $\mathrm{mg} / \mathrm{kg}$ (minimal inhibitory dose ) (15) multiple doses were tried and the minimal inhibitory doses used in all experiments were as follows : Aspirin $(2.5 \mathrm{mg} / \mathrm{kg})$, Mefenamic $\operatorname{acid}(8.33 \mathrm{mg} / \mathrm{Kg})$, Ibuprofen $(10 \mathrm{mg} / \mathrm{Kg})$ and meloxicam $(0.0033 \mathrm{mg} / \mathrm{kg})$ depending on the outcome of the effects of these drugs on ovulation. .A pilot study was applied on mature female mice,NSAIDs doses were administered three time daily ,starting at proestrous phase of estrous cycle( $8 \mathrm{am} 4 \mathrm{pm} \& 12 \mathrm{am}$ ) for two days .Mice were killed at metestrous phase and ova flushed from the oviduct to determine the ovulatory rate.

\section{Hormonal Assay:}

Luteinizing hormone $(\mathrm{LH}) \&$ follicular Stimulating hormone $(\mathrm{FSH})$ progesterone and estradiol were assayed by measuring their levels in serum using prepared kits of Radio - Immunoassay (RIA) (16).

\section{Detectionof Phases of Estrous Cycle:}

Phases of estrous cycle of the mice were detected and recorded using vaginal smears. Smears were then spread on a clean slideand fixed on a flame before staining with $1 \%$ aqueous methylene blue for 3-5 minutes. Stained smears were then washed with tap water, air dried and examined using a light microscope at 10X magnification to determine phases of the estrous cycle (17).

\section{Flushing of ova:}

The dissection of the ovaries from the oviduct was carefully performed with a fine surgical scissors,and then a tuberculin syringe (30 gauges) with blunt ended needle filled with $1 \mathrm{ml}$ of D.W was inserted into the fimbriated end of the oviduct and held in place with fine surgical forceps. The ova were then flushed and recovered into a Petri dish with D.W delivered from the syringe. Ova obtained were identified and counted using a dissecting microscope under 2.5X,16X magnification (18).

\section{Preparation of Blood Sera:}

Blood was collected from treated animals \& controls by cardiac puncture fromanasthetized animals with diethylether. Blood left to clot for 30 minutes at room temperature then, centrifuged using conical test tubes for 15 minutes at $2500 \mathrm{rpm}$. Prepared sera were then transferred into a plastic vial and stored in a deep freezer ($20^{\circ} \mathrm{C}$ ) until used for hormonal determination (19).

\section{Animals:}

Animals of the present study ( $\mathrm{n}=36 \mathrm{female})$ were subdivided into 6groups ( 6 animals/group).The 1 st group received aspirin s.c,the2nd group received aspirin oral, the3rd group received mefenamic acid ,the 4th group received ibuprofen ,the $5^{\text {th }}$ group received meloxicam. doses mentioned above , and the $6^{\text {th }}$ group received D.W as acontrol group. In all cases NSAIDs doses and the distilled water were administered three time daily, starting at proestrous phase of estrous cycle $(8 \mathrm{am} \& 4 \mathrm{pm} \& 12 \mathrm{am})$ on the same day. Before killing the anaesthetized animals at metestrous phase, blood was collected and sera prepared and stored at $-20^{\circ} \mathrm{C}$ for subsequent hormonal assay. The whole reproductive system was quickly removed after killing, and was immersed in a Petri-dish filled with an in vitro D.W kept at $37^{\circ} \mathrm{C}$. Both ovaries were quickly dissected out using fine surgical scissors, cleared from surrounding non-ovarian tissue under the dissecting microscope and weighed (after drying by filter papers) using electronic precision balance .The uteri were then quickly dissected out slightly at the tubouterine junction from one end and immediately close to the internal orifice of the cervix from the other end, they were cleared from the surrounding non-uterine tissue.

\section{Results}

\section{Morphological change :}

Ovaries :of the control group that received distilled water showed slight congestion larger in size with smooth surface while animals that received $2.5 \mathrm{mg} / \mathrm{kg}$ of aspirin seemed to be enlarged, congested with cystic appearance compared to those received $8.33 \mathrm{mg} / \mathrm{kg}$ of mefenamic acid and $10 \mathrm{mg} / \mathrm{kgof}$ ibuprofen that showed more obvious cystic appearance with the same enlargement and congestion, while those received $0.0033 \mathrm{mg} / \mathrm{kg}$ of meloxicam showed very obvious cystic appearance with the same congestion as the previous three groups as in fig $1,2,3,4$ and 5 .

Uteri :of the control group that received distilled water showed congestion with very slight prominent blood vessels while animals that received $2.5 \mathrm{mg} / \mathrm{kg}$ of aspirin seemed to be congested with prominent blood vessels and lumen filled with fluid compared to those received $8.33 \mathrm{mg} / \mathrm{kg}$ of mefenamic acid and $10 \mathrm{mg} / \mathrm{kgof}$ ibuprofen and those received $0.0033 \mathrm{mg} / \mathrm{kg}$ of meloxicam that showed the same changes as in fig 1,2,3,4 and 5.. 


\section{Change in ovarian and uterus weight:}

ovaries: No significant changes $(\mathrm{P}>0.05)$ were seen in the ovarian weight between control and animals that received aspirin (s.c or oral) and mefenamic acid as in table 1,2,3, respectively, and significant decrease $(\mathrm{P}<$ 0.05 ) were seen in the ovarian weight between controls and each of animals that received ibuprofen\& meloxicam as in table 4,5,respectively. While there is no significant changes( $\mathrm{P}>0.05$ ) were seen between animals that received aspirin(s.c) and those received mefenamic acid, ibuprofen, and meloxicam as in table 6.

Uteri:No significant changes ( $\mathrm{P}$ 0.05) were seen in the uterine weight between controls and each of animals that received aspirin(s.c or oral) as in table1,2 respectively and significant decrease $(\mathrm{P}<0.05)$ were seen in the ovarian weight between controls and each of animals that received mefenamic acid ,ibuprofen\& meloxicam as in table $3,4,5$ respectively. While there is no significant changes( $P>0.05)$ were seen between animals that received aspirin(s.c) and those received mefenamic acid, ibuprofen, and meloxicam as in table 6,

\section{Number of flushed ova:}

A highly significant decrease $(\mathrm{P}<0.05)$ were seen in the number of ova flushed was seen between the control and female mice that received aspirin (s.c and oral) ibuprofen, and meloxicam table $1,2,4.5$ respectively and highly significant decrease $(\mathrm{P}<0.001)$ were seen in the number of ova flushed was seen between the control and female mice that received mefenamic acid as in table 3 while no significant difference $(P>0.05)$ was seen between each of animals that received aspirin(s.c) and those received mefenamic acid, ibuprofen, and meloxicam, as in table 6 .

\section{Hormonal changes:}

No significant changes $(\mathrm{P}>0.05)$ were seen in the levels of LH FSH Progesterone nor Estradiol collected from the treated animals between controls and each of animals that received aspirin, mefenamic acid, ibuprofen and meloxicam) as in table1,2,3,4,5 respectively and no significant difference $(\mathrm{P}>0.05)$ was seen between each of animals that received aspirin(s.c) and those received mefenamic acid, ibuprofen, and meloxicam, as in table 6 .

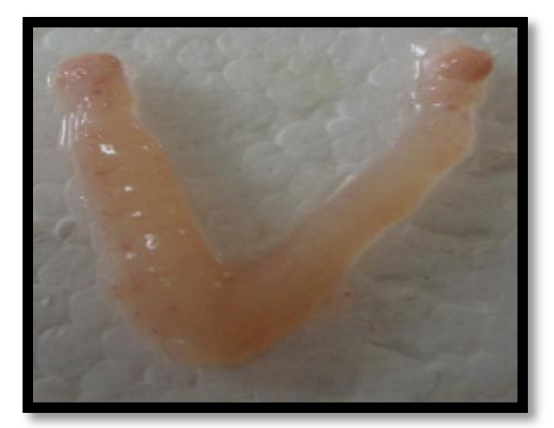

Figure(1):Genital system of mature female mouce at metestrous phase, (control group)

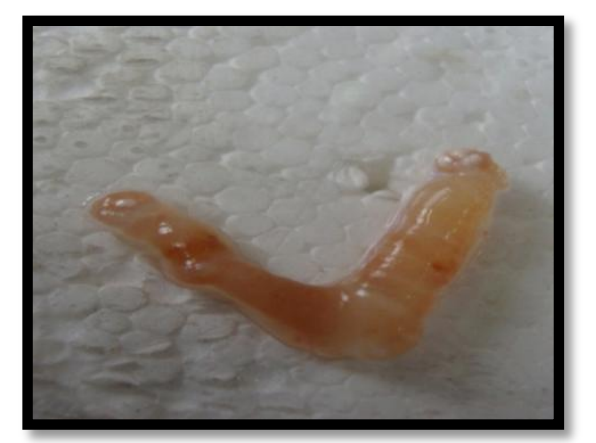

Figure(2):Genital system of mature female mouce at metestrous phase, (Aspirin group) 


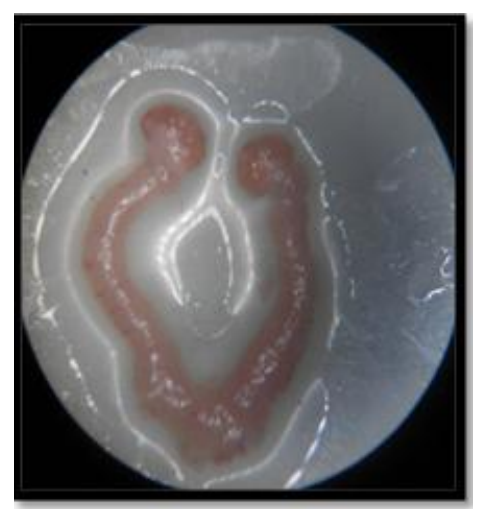

Figure(3):Genital system of mature female mouce at metestrous phase, (Mefenamic acid group)

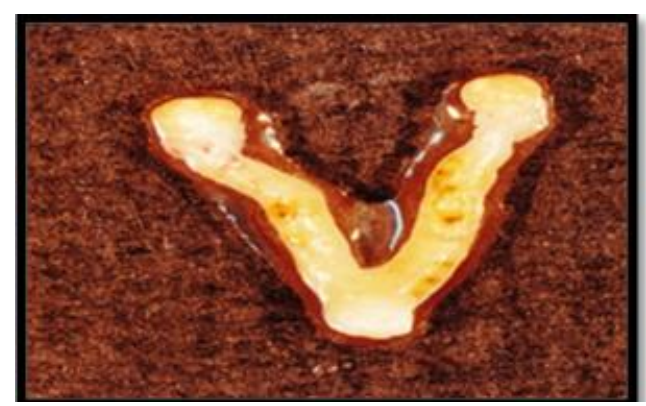

Figure(4):Genital system of mature female mouce at metestrous phase, (Meloxicam group)

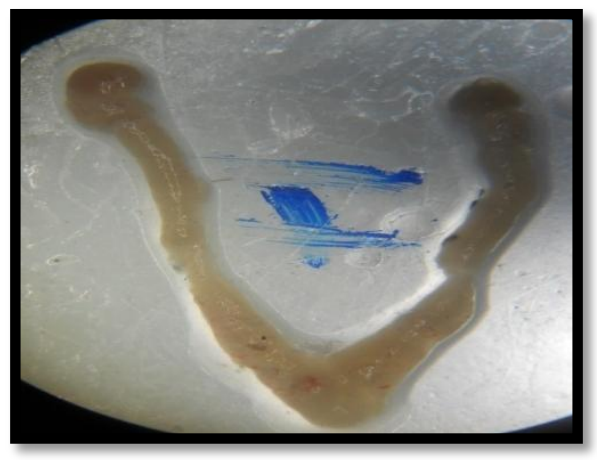

Figure(5):Genital system of mature female mouce at metestrous phase, (Ibuprofen group)

Table (1): Changes in weight of the ovaries uteri and difference in number of ova flushed \& changes of LH, FSH, Progesterone, \& Estradiol levels ( cycling female mice treated with aspirin s.c, on day of proestrous phase ).

\begin{tabular}{|c|c|c|c|}
\hline Parameter & Control & Aspirin s.c & P value \\
\hline Uterine wt & $52.35 \pm 0.76$ & $31.10 \pm 0.1$ & $0.13^{\mathbf{0}}$ \\
\hline Ovarian wt & $7.06 \pm 0.07$ & $5.93 \pm 0.06$ & $0.27^{\circ}$ \\
\hline Number of ova flushed & $9.83 \pm 0.872$ & $4.16 \pm 0.872$ & $0.001^{* *}$ \\
\hline \#LH & $4.31 \pm 0.066$ & $4.17 \pm 0.232$ & $0.57^{\circ}$ \\
\hline \#FSH & $8.38 \pm 0.083$ & $8.32 \pm 0.122$ & $0.70^{\circ}$ \\
\hline \#\#Prog. & $17.19 \pm 0.383$ & $16.88 \pm 0.131$ & $0.46^{\circ}$ \\
\hline \#\#\#Estradiol & $20.85 \pm 0.174$ & $20.39 \pm 0.43$ & $0.27^{\circ}$ \\
\hline
\end{tabular}

Table (2): Changes in weight of the ovaries uteri and difference in number of ova flushed \& changes of LH, FSH, Progesterone , \& Estradiol levels ( cycling female mice treated with aspirin oral, on day of proestrous phase ).

\begin{tabular}{|c|c|c|c|}
\hline Parameter & Control & Aspirin oral & P value \\
\hline Uterine wt & $52.35 \pm 0.76$ & $29.21 \pm 0.14$ & $0.19^{\circ}$ \\
\hline
\end{tabular}




\begin{tabular}{|c|c|c|c|}
\hline Ovarian wt & $7.06 \pm 0.07$ & $5.53 \pm 0.01$ & $0.29^{\circ}$ \\
\hline Number of ova flushed & $9.83 \pm 0.872$ & $4.33 \pm 0.843$ & $0.001^{* *}$ \\
\hline \# LH & $4.31 \pm 0.066$ & $4.31 \pm 0.093$ & $0.96^{\circ}$ \\
\hline \# FSH & $8.38 \pm 0.083$ & $8.43 \pm 0.119$ & $0.76^{\circ}$ \\
\hline \#\#Prog. & $17.19 \pm 0.383$ & $16.79 \pm 0.105$ & $0.34^{\circ}$ \\
\hline \#\#\#Estradiol & $20.85 \pm 0.174$ & $20.47 \pm 0.307$ & $0.31^{\circ}$ \\
\hline
\end{tabular}

Table (3): Changes in weight of the ovaries uteri and difference in number of ova flushed \& changes of LH, FSH, Progesterone, \& Estradiol levels ( cycling female mice treated with mefenamic acid, on day of proestrous phase ).

\begin{tabular}{|c|c|c|c|}
\hline Parameter & Control & Mefenamic Acid & P value \\
\hline Uterine wt & $52.35 \pm 0.76$ & $29.88 \pm 0.59$ & $0.04^{*}$ \\
\hline Ovarian wt & $7.06 \pm 0.07$ & $6.56 \pm 0.01$ & $0.7^{\circ}$ \\
\hline Number of ova flushed & $9.83 \pm 0.872$ & $3.33 \pm 0.421$ & $<0.001^{* *}$ \\
\hline \# LH & $4.31 \pm 0.066$ & $4.10 \pm 0.076$ & $0.06^{\circ}$ \\
\hline \# FSH & $8.38 \pm 0.083$ & $8.20 \pm 0.103$ & $0.19^{\circ}$ \\
\hline \#\#Prog. & $17.19 \pm 0.383$ & $16.40 \pm 0.178$ & $0.09^{\circ}$ \\
\hline \#\#\#Estradiol & $20.85 \pm 0.174$ & $20.12 \pm 0.331$ & $0.08^{\circ}$ \\
\hline
\end{tabular}

Table (4): Changes in weight of the ovaries uteri and difference in number of ova flushed \& changes of LH, FSH , Progesterone, \& Estradiol levels ( cycling female mice treated with Ibuprofen, on day of proestrous phase

\begin{tabular}{|c|c|c|c|}
\hline \multirow{2}{*}{ Parameter } & Control & Ibuprofen & P value \\
\hline Uterine wt & $52.35 \pm 0.76$ & $24.25 \pm 0.71$ & $0.02^{*}$ \\
\hline Ovarian wt & $7.06 \pm 0.07$ & $4.41 \pm 0.06$ & $0.02^{*}$ \\
\hline Number of ova flushed & $9.83 \pm 0.872$ & $4.33 \pm 0.988$ & $<0.002^{*}$ \\
\hline \# LH & $4.31 \pm 0.066$ & $4.27 \pm 0.196$ & $0.84^{\mathbf{0}}$ \\
\hline \# FSH & $8.38 \pm 0.083$ & $8.45 \pm 0.127$ & $0.64^{\mathbf{0}}$ \\
\hline \#\#Prog. & $17.19 \pm 0.383$ & $16.92 \pm 0.165$ & $0.53^{\mathbf{0}}$ \\
\hline \#\#\#Estradiol & $20.85 \pm 0.174$ & $20.80 \pm 0.349$ & $0.91^{\mathbf{}}$ \\
\hline
\end{tabular}

Table (5): Changes in weight of the ovaries uteri and difference in number of ova flushed \& changes of LH, FSH, Progesterone, \& Estradiol levels ( cycling female mice treated with Meloxicam, on day of proestrous phase ).

\begin{tabular}{|c|c|c|c|}
\hline Parameter & Control & Meloxicam & P value \\
\hline Uterine wt & $52.35 \pm 0.76$ & $25.78 \pm 0.8$ & $0.03^{*}$ \\
\hline Ovarian wt & $7.06 \pm 0.07$ & $4.60 \pm 0.08$ & $0.04^{*}$ \\
\hline Number of ova flushed & $9.83 \pm 0.872$ & $5.1 \pm 0.872$ & $<0.004^{*}$ \\
\hline \# LH & $4.31 \pm 0.066$ & $4.32 \pm 0.123$ & $0.96^{\circ}$ \\
\hline \# FSH & $8.38 \pm 0.083$ & $8.50 \pm 0.108$ & $0.40^{\circ}$ \\
\hline \#\#Prog. & $17.19 \pm 0.383$ & $16.91 \pm 0.168$ & $0.52^{\circ}$ \\
\hline \#\#\#Estradiol & $20.85 \pm 0.174$ & $20.87 \pm 0.275$ & $0.94^{\circ}$ \\
\hline
\end{tabular}

Table (6) :P value according to multiple comparisons test for changes in weight of uteri ,ovaries and changes in n. of flushed ova and changes of LH, FSH, Progesterone, \& Estradiol levels comparsion with Aspirin s.c

\begin{tabular}{|l|c|c|c|c|}
\hline \multicolumn{1}{|c|}{ Parameter } & $\begin{array}{c}\text { Aspirin s.c } \\
\text { Vs. } \\
\text { Aspirin oral }\end{array}$ & $\begin{array}{c}\text { Aspirin s.c } \\
\text { Vs. } \\
\text { Mefenamic acid }\end{array}$ & $\begin{array}{c}\text { Aspirin } \\
\text { Vs. } \\
\text { Ibuprofen }\end{array}$ & $\begin{array}{c}\text { Aspirin } \\
\text { Vs. } \\
\text { Meloxicam }\end{array}$ \\
\hline Uterine Weight. & $0.91^{\circ}$ & $0.92^{\circ}$ & $0.60^{\circ}$ & $0.69^{\circ}$ \\
\hline Ovarian Weight. & $0.7^{\circ}$ & $0.63^{\circ}$ & $0.14^{\circ}$ & $0.24^{\circ}$ \\
\hline $\begin{array}{c}\text { Number of ova } \\
\text { flushed }\end{array}$ & $0.89^{\circ}$ & $0.41^{\circ}$ & $0.90^{\circ}$ & $0.43^{\circ}$ \\
\hline \#LH & $0.57^{\circ}$ & $0.77^{\circ}$ & $0.75^{\circ}$ & $0.58^{\circ}$ \\
\hline \# FSH & $0.56^{\circ}$ & $0.45^{\circ}$ & $0.47^{\circ}$ & $0.30^{\circ}$ \\
\hline \#\#Prog. & $0.61^{\circ}$ & $0.054^{\circ}$ & $0.84^{\circ}$ & $0.88^{\circ}$ \\
\hline \#\#\#Estradiol & $0.87^{\circ}$ & $0.58^{\circ}$ & $0.42^{\circ}$ & $0.31^{\circ}$ \\
\hline
\end{tabular}

Values are mean \pm standard error $(\mathrm{SE}){ }^{\circ}=$ non significant difference

* = significant difference \#levels of hormones in $(\mathrm{mIu} / \mathrm{ml})$
$* *=$ highly significant difference

\#\# levels of hormones in $(\mathrm{ng} / \mathrm{ml})$

\#\#\# levels of hormones in $(\mathrm{pg} / \mathrm{ml})$ 


\section{Discussion:}

The morphological changes observed in cycling female mice treated with aspirin, mefenamic acid ,ibuprofen and meloxicam on day of proestrous namely : intense organ congestion, cystic appearance of the ovaries and enlargement of the organs are clear indication of pronounced inflammatory response. Vascular changes induced by aspirin , mefenamic acid, ibuprofen and meloxicam (vasodilation \&increased permeability ) (20) as well as the normal physiological morphological changes associated with ovulatory process (21) have a combined effect to give such outcome that observed on ovarian and uterine morphological changes. All these inflammatory changes occurring during ovulation are thought to be mediated mainly by :PGs(PGE2), (PGI2) and histamine(22). Moreover,PGF2 $\alpha$ is a well known factor in terminating inflammatory changes associated with ovulation (23), and its synthesis is stimulated by gonadotropins (FSH/LH)(24) which are known to increase during this period. These interactions suggest that inhibition of PGF2 $\alpha$ by NSAIDs administration may block or prevent the termination of the inflammatory process and allowing it to extend longer than normal and the slight difference observed between the different NSAIDs may reflect the difference in potency ofPGF2 $\alpha$ inhibition and anti-inflammatory action between the different NSAIDs according to the difference in their selectivity towards COX enzyme selectivity and in their pharmacokinetic properties(25). The cystic appearance of ovaries of experimental animals was due to failure of ovulation of certain number of graafian follicles which has been turned into luteinized unruptured follicles. It has been reported that, presence of PGF2 $\alpha$ is critical factor in ovulation $(5,26)$. Inhibition of PG synthesis in the preovulatory follicles by the four NSAIDs treated subgroups hinders completion of the ovulatory process leading to the failure of the follicular rupture and hence formation of cysts (27) which gave rise to the cystic appearance of ovaries in treated animals. The vasodilation and the consequent slow blood movement caused by nsaids in these organs due to the suppression of several substances including PGF2 $\square$. Also as it is well known that several platelet substances such as: collagen, thrombin, TXA2, adenosine diphosphate (ADP) and dense and alpha granules produce platelet activation(28). Moreover activated platelets, release calcium from the dense granules into the cytoplasm (29) and calcium causes platelets contraction with a further release of serotonin, ADP, and arachidonate. Arachidonic acid, then converted into TXA2 by the COX enzyme, this enzyme could be irreversibly inhibited by low-dose aspirin treatment \& reversibily inhibited by low-dose mefenamic acid, ibuprofen and meloxicam thus, vasoconstriction and platelet aggregation may be avoided (30). The above process may improve blood flow to these organs, uteri\& ovaries and this lead to congestion. Such a disturbances in the vascular blood supply of the uterine wall may explain the significant decrease in the uterine weight. Significant decrease in ovarian weight in animal that received nsaids may due to decrease number of ova in ovary compare to control that received distal water it could be due to the balanced changes in the main components of ovarian weight i.e.: number of corpora lutea, growing and Graafian follicles. Regarding reduction in ovulation rate (number of flushed ova) which was reduced significantly in treated animals compared to control group, the underlying cause could be due to incomplete central inhibition of gonadotopin release (FSH and LH which are known to be a key hormones for ovulation (31).Aspirin administration in a very high dose caused a complete cessation of ovulation with a significant decrease in both FSH and LH, this decrease was thought to be due to suppression of PGE2 by aspirin centrally in hypothalamusand locally on the ovarian level PGs(32). Results of the present study indicate that low doses of NSAIDs $(2.5 \mathrm{mg} / \mathrm{kg}$.bw of aspirin, $8.33 \mathrm{mg} / \mathrm{Kg}$ mefenamic acid, $10 \mathrm{mg} / \mathrm{Kg}$ ibuprofen and $0.0033 \mathrm{mg} / \mathrm{kg} . \mathrm{bw}$ of meloxicam) were unsuccessful in inducing any significant changes in the serum level of (FSH, LH, progesterone, and estrediol ), as well as,the low doses of aspirin were unsuccessful in inducing any significant changes in the serum level of both gonadotropins $(\mathrm{FSH} / \mathrm{LH})(33)$ and this effect seems to have been mainly on the ovarin level. Yen et al,have shown that PGs have little direct effect on gonadotropin secreted from the pituitary, while NSAIDs seems to suppress these hormones at the hypothalamic level by inhibition on GnRH release $(34,35)$, and this what happened when high doses of aspirin are used. PG levelsare elevated in the mature ovarian follicles due to the ovulatory LH surge(35). Several reports have shown that, ovulation can be inhibited by NSAIDs despite of undetectable changes in several key hormones of ovulation (FSH, LH,E2\&P4), suggesting that local ovarian factors are the predominant driving force in ovulation(26). Many authors reported that, there is a marked increase in intrafollicular levels of PGs (E and F series) shortely before ovulation(36). Moreover it has also been reported that, low dose of aspirin partially reduced follicular level of PGE2 and PGF2 $\alpha$ and in order to abolish ovulation totally, NSAIDs must be administered in high dose(37). Women taking anti-PGs drugs, suffer from luteinization of graafian follicle, to produce a syndrome referred to as luteinized unruptured follicle syndrome(38). Thus failure of the dose levels of the four subgroups of NSAIDs that are used in present study to induce any significant changes in gonadotropins ( $\mathrm{FSH} / \mathrm{LH})$ may be due to several causes : NSAIDs doses used was too low to induce suppression of hypothalamic PGE2(39). the other possibility is that NSAIDs acted locally at ovarian level without any effect on gonadotropins (FSH/LH) (40). 


\section{Reference:}

[1]. Lippincott's (2012): Illustrated reviews: Pharmacology $5^{\text {th }}$ ed. Anti-inflammatory drugs. New York.

[2]. Abransom, S.B. and Weissman, G. (1989) The mechanisms of action of nonsteroidal anti-inflammatory drugs. Arthr Rheum. 32 (Suppl 3):1-9

[3]. Stuart J. Warden, PT, PhD, FACSM (April 2010) "Prophylactic Use of NSAIDs by Athletes:A Risk/Benefit Assessment". The Physician and SportsMedicine. 38 (1): 132-138

[4]. Bertram G.Katzung . Basic and clinical pharmacology $.12^{\text {th }}$ edition $p, 636$

[5]. Espey LL (1980) Ovulation as an inflammatory response-a hypothesis. Biol Reprod 22,73-106

[6]. Espey LL and Lipner H (1994) Ovulation. In Knobil E and Neill JD (eds) Physiology of Reproduction, vol 1. Raven Press, New York, pp 725-781

[7]. Eppig JJ. Prostaglandin E2 stimulates cumulus expansion and hyaluronic acid synthesis by cumuli oophori isolated from mice. Biol Reprod 1981; 25:191-195

[8]. Hizaki H, Segi E, Sugimoto Y, Hirose M, Saji T, Ushikubi F, Matsuoka T, Noda Y, Tanaka T, Yoshida N et al. Abortive expansion of the cumulus and impaired fertility in mice lacking the prostaglandin E receptor subtype EP 2. Proc Natl Acad Sci USA 1999;96:10501-10506

[9]. Markosyan N, Duffy DM. Prostaglandin E2 acts via multiple receptors to regulate plasminogen-dependent proteolysis in the primate periovulatory follicle. Endocrinology 2009;150:435-444.

[10]. Sirois J. Induction of prostaglandin endoperoxide synthase-2 by human chorionic gonadotropin in bovine preovulatory follicles in vivo. Endocrinology 1994;135:841-848

[11]. Duffy DM, Stouffer RL. Follicular administration of a cyclooxygenase inhibitor can prevent oocyte release without alteration of normal luteal function in rhesus monkeys. Hum Reprod 2002;17:2825-2831

[12]. Peters MW, Pursley JR, Smith GW. Inhibition of intrafollicular PGE2 synthesis and ovulation following ultrasound-mediated intrafollicular injection of the selective cyclooxygenase-2 inhibitor NS-398 in cattle J Anim Sci 2004;82:1656-1662

[13]. Lim H, Paria BC, Das SK, Dinchuk JE, Langenbach R, Trzaskos JM et al. Multiple female reproductive failures in cyclooxygenase-2-deficient mice. Cell1997;91:197

[14]. Matsumoto H, Ma W, Smalley W, Trzaskos J, Breyer RM \& Dey SK2000 Diversification of cyclooxygenase-2-derived prostaglandins in ovulation and implantation. Biology of Reproduction 641557-1565

[15]. Al-Atrakji-M.Q (2006): Pharmacological effects of low-13. doses of aspirin on reproductive syste in pre-mature female mice. A thesis submitted to the college of medicine, university of Baghdad

[16]. Linksey, M.T.; Cain, T.P.; Caldwell, B.W. (1991): Lab. oratory evaluation of the infertile couple and monitoring of gonadotropin therapy. J. Clin. Immunoassay. 14: 29-32 (Internet)

[17]. Humason, GL (1997): Animal tissue techniques. 515. th ed., the Johs Hopkins Uniersity Press Baltimore and London

[18]. Bennet-J.P and Vickery-B.H(1970):Rats and mice in re16. production and breeding techniques for laboratory animals(ed.)Hafez.E.S.E.PP:299-315.John Wiley\&Sons Ltd

[19]. Hitzelberg, Lundgren and Phillips (1985): Laboratory 17. Manual for Basic Biomethodology of Laboratory Animals, Vol. I (Internet).

[20]. Haslett-C; Chilvers-E.R; Hunter .J.A.A; and Boon-19. N.A.(1999):Davidsons principles and practice of medicine 8thed ., Churchill Livingstone.

[21]. Eisenberg-E; Kiatai-H; Kobayashi-Y; Santulli-R; 20. Wallach-E.(1984): Gonadotropin releasing hormone effect on the in vitro perfussed rabbit ovary. B iol. Reprod.30:1216-1222.

[22]. Hammada-Y; Bronson-R.A.; Wright K.H.andWallach.E.21. E.(1977):Ovulation in the perfused rabbit ovary : the influence of prostaglandin inhibitors. Biology of reproduction.17,58-63.

[23]. Murdoch WJ; CavenderJ.L;(1989):Effects of indo meth acin on vascular architecture of pe-ovulatory ovin follicles possible implication in the lutenizedunruptured follicle syndrome fert-steril.51;1:153-155.

[24]. Espey. LL; Stein-V.I; Dumitrescu-J.(1982): Survey of anti-inflammatory agents\&related drugs a inhibitors of ovulation in the rabbit.Fertility-Sterility.38(2):238-247.

[25]. Vane, JR; Bakhle, YS; Botting, RM (1998): 24. Cyclooxygenases 1 and 2. Ann Rev. Pharmacol. Toxicol. 38: 97-100.

[26]. Killick, S. and Elstein, M. (1987): Pharmacologic 25. production of luteinized unruptured follicles by prostaglandin synthetase inhibitors. Fertil. Steril. 47, 773-777.

[27]. Silva-M.D \& Reeves-J.J(1985): Indomethacin inhibition 27. of ovulation in cow.J.Reprod.fert.75:547-54. [28]. Ojanen, R.; Kaukinen, L.; Seppala, E.; Kaukinen, S.; Vapattalo, H. (2003): Single dose of acetylsalicylic acid prevent thromboxane release after ischaemia. 54(5): 986-9

[28]. Ganong, W.F. (2003): Review of medical physiology. A LANGE medical book, $21^{\text {st }}$ ed. , McGraw-Hill.

[29]. Cheng, Yan; Austin, S.C.; Rocca, B.; Koller, B.H.; Coffman, T.M.; Grosser, T.; Lawson, J.A.; Fitz Gerald, G.A. (2002): Role of prostacyclin in the cardiovascular response to thromboxane $\mathrm{A}_{2}$. Science 19; 296(5567): 539-41.

[30]. Shalev-E; Leung-P.C (2003): Gonadotropin-releasing hormone and reproductive medicine .J.OBSTET.GYNECOL.CAN.25 (2):98113

[31]. Al-Bayati-S.A(2002):The effect of aspirin on female 28. reproductive system in mice. A thesis submitted to the college of medicine, university of Baghdad.1423.

[32]. Al-Rubayi-F.K(2004):Pharmacological effects of low-doses of aspirin on ovulatory state and corpus luteum functions in mature female mice. A thesis submitted to the college of medicine, university of Baghdad.

[33]. Yen-S.S.C; Jaffe-R.B; Barbieri-R.L(1999): Reproductive endocrinology.physiology,pathophysiology and clinical management. 4thed.W.B.Sauners company

[34]. Ojeda-S.R;Negro-V; McCann-S.M.(1982):Evidence of involvement of alpha adrenergic receptors in nor-epinephrinic-induced prostaglandin E2 AND LH releasing hormone release from the median eminence.endocrinology.110:409-412.

[35]. Ushikubi-F; Sugimoto-Y; Ichikawa-A; Narumiya-S (2000): Role of prostanoids revealed from studies using mice lacking specific postanoid receptors.J.P.J.Pharmacol.83(4):279-85.

[36]. Espey LL (1983): comparsion of the the effect of NSAIDs. \& steroidal anti-inflammatory agents on prostaglandin production during ovulation in the rabbit. Prostaglandin.26(1):33-41.

[37]. NormanRJ. (2001):ReproductiveconsequencesofCOX-2inhibition.Lancet;358:1287-8.

[38]. Chandra-J; Bhatnagar-S.K. (2002): Antipyretics in children. Indian .J. Pediatr.69(1):69-74.

[39]. Tokuyama O, Nakamura Y, Muso A, Honda K, Ishiko O and Ogita S (2001) Expression and distribution of cyclooxygenase-2 in human periovulatory ovary. Int J Mol Med 8, 603-606 